\title{
Produzindo o sagrado pelas mídias sociais: a interação dos fiéis com o Templo de Salomão no Instagram
}

\author{
Producing the sacred by social media: The faithful's interaction with the \\ Solomon's Temple on Instagram
}

\section{Produciendo el sagrado por los medios sociales: la interacción de los fieles con el Templo de Salomón en Instagram}

Jênifer Rosa de Oliveira ${ }^{l}$

Magali do Nascimento Cunha ${ }^{2}$

\begin{abstract}
Resumo
Os imaginários sociais são criações coletivas que permitem que os sujeitos se reconheçam e partilhem seu universo simbólico, e que por isso dão liga a uma sociedade. Este processo constante de apropriação e transmissão dos imaginários alimenta e é alimentado, dentre outras fontes, pela mídia. Neste trabalho, propomo-nosa identificar como as mídias sociais atuam nesse processo coletivo de reapropriação dos imaginários sobre o sagrado ao permitir que os usuários interajam com o conteúdo compartilhado e também entre si, estimulando a formação de vínculos afetivos. Para fundamentar a compreensão deste processo comunicacional, recorremos às Teorias do Imaginário. A trajetória metodológica inclui um estudo do perfil do Templo de Salomão da Igreja Universal do Reino de Deus no Instagram, por meio de análise iconográfica de fotografias com o maior número de "curtidas", postadas nos meses posteriores à inauguração, combinada com uma interpretação dos comentários dos fiéis referentes a elas.
\end{abstract}

Palavras-Chave: Imaginário Social. Templo. IURD. Mídias. Sagrado.

\begin{abstract}
The social imaginary are collective creations that allow subjects to recognize and share their symbolic universe, and therefore give the alloy to a society. This constant process of appropriation and transmission of imaginaries feeds and is fed, among other sources, by the media. In this article to identify how social media networks operate in this collective process of re-appropriation of the imaginary of the sacred by allowing users to interact with the shared content and also with each other, stimulating the formation of emotional bonds. To substantiate the understanding of this communication process, we turn to the authors of Imaginary Theories. The methodology includes a study of profile of the Temple of Solomon of the Universal Church of the Kingdom of God on Instagram through iconographic analysis of photographs with the major number of "likes" posted on the months after the inauguration, combined with an interpretation of comments from believers concerning them.
\end{abstract}

Keywords:Social Imaginary. Temple. IURD. Media. Sacred.

\begin{tabular}{|c|c|}
\hline \multirow{3}{*}{ 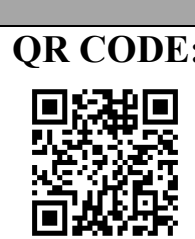 } & Acesse este artigo online \\
\hline & $\begin{array}{l}\text { Website: } \\
\text { http://www.revistas.ufg.br/index.php/ci }\end{array}$ \\
\hline & $\begin{array}{l}\text { DOI: } \\
\text { http://dx.doi.org/10.5216/ci.v19i2.3678 } \\
4\end{array}$ \\
\hline
\end{tabular}

\section{Resumen}

Los imaginarios sociales son creaciones colectivas que permiten a los individuos reconocerse y compartir su universo

\footnotetext{
${ }^{1}$ Mestranda do Programa de Pós-Graduação em Comunicação da Universidade Metodista de São Paulo (UMESP). Graduada em Comunicação Social pela Universidade Federal de Minas Gerais (UFMG). Membro do MIRE (Grupo de Pesquisa Mídia Religião e Cultura). Brasil, São Paulo, São Paulo. E-mail: jeniferdeoliveira@gmail.com 2 Doutora em Ciências da Comunicação pela Universidade de São Paulo (USP). Mestre em Memória Social pela Universidade Federal do Estado do Rio de Janeiro (UNIRIO). Professora da Universidade Metodista de São Paulo (UMESP), vinculada ao Programa de Pós-Graduação em Comunicação. Líder do grupo de pesquisa MIRE - Mídia, Religião e Cultura. Brasil, São Paulo, São Paulo. E-mail: magali.cunha@metodista. br.
}

Comun. \& Inf., Goiânia, GO, v. 19, n. 2, p. 35-52, jul./dez. 2016. 
simbólico, y por lo tanto dan cohesión a la sociedad. Este constante proceso de apropiación y transmisión de los imaginarios alimenta y se alimenta de, entre otras fuentes, los medios de comunicación de masas. En este trabajo se propone identificar cómo los medios de comunicación sociales operan en este proceso de reapropiación del imaginario colectivo sobre lo sagrado, al permitir a los usuarios interactuar con el contenido compartido y también entre sí, estimulando la formación de vínculos afectivos. Para fundamentar la comprensión de este proceso de comunicación, utilizamos las Teorías del Imaginario. La metodología incluye un estudio del perfil del Templo de Salomón de la Iglesia Universal del Reino de Dios en Instagram a través del análisis iconográfico de fotografías con más "me gustas" publicadas en el mes siguiente a su inauguración, junto con una interpretación de los comentarios de los fieles en estas fotografías.

Palabras claves: Imaginario social. Templo. IURD. Medios de comunicación. Sagrado.

\section{INTRODUÇÃO}

一 $\begin{aligned} & \text { o dia } 30 \text { de julho de 2014, no bairro do Brás, em São Paulo, foi inaugurado } \\ & \text { o maior santuário religioso do Brasil. A cerimônia, que contou com a } \\ & \text { presença de personalidades políticas importantes, como a própria presidenta }\end{aligned}$ Dilma Rousseff, abriu as portas do Templo de Salomão, sede mundial da Igreja Universal do Reino de Deus (IURD), que foi construído a partir dos relatos do Antigo Testamento da Bíblia cristã que descrevem o templo sagrado dos judeus daquela época.

Com $126 \mathrm{~m}$ de comprimento, $104 \mathrm{~m}$ de largura e $55 \mathrm{~m}$ de altura, embora carregue o nome de Salomão, construtor do primeiro Templo em Jerusalém, o empreendimento da IURD é, na verdade, uma réplica do Templo de Herodes, o Segundo Templo, muito maior e mais suntuoso, construído após a destruição do Templo de Salomão pelos babilônios por volta do ano 580 a.C. Entretanto, o Templo da IURD conta com reproduções de elementos sagrados que o primeiro Templo abrigava, como, por exemplo, uma cópia da Arca da Aliança que, de acordo com a mitologia judaica, guardava os Dez Mandamentos.

Para a construção de sua versão do Templo de Salomão, que ocupa uma área equivalente a cinco campos de futebol, estima-se que a IURD tenha gastado cerca de 680 milhões de reais nos quatro anos de duração da obra. Pedras importadas de Hebron, em Israel, doze oliveiras uruguaias que reproduzem o Monte das Oliveiras e vitrais dourados foram utilizados na construção do empreendimento.

De acordo com informações disponíveis no site do Templo de Salomão da IURD, a ideia de construí-lo surgiu quando Edir Macedo, fundador e liderança máxima da igreja, em uma visita a Israel, sentiu o desejo de que as pessoas que não pudessem ir até lá tivessem acesso, de alguma forma, às maravilhas que a Bíblia narra sobre a Terra Santa. Daí nasceu a ideia de se fazer uma réplica do Templo sagrado descrito no livro dos cristãos, mas que, diferente 
daquele, que era reservado apenas ao uso daqueles que professavam a fé judaica, pudesse ser acessado por todos, com a mesma aura de sacralidade que existia no antigo Templo.

Desde que foi inaugurado, a IURD adotou uma série de regras específicas para o santuário que não vigoram nas demais igrejas e que contribui para que se construa um imaginário de sagrado em torno dele. Por exemplo, não é permitido filmar ou fotografar os espaços internos, adentrar ao local portando telefones celulares ou após as cerimônias religiosas terem se iniciado. A igreja produziu um vídeo no qual um pastor orienta os fiéis acerca dessas regras e também das roupas mais apropriadas para se trajar ao frequentar o Templo ${ }^{3}$.

Além de regras específicas para acesso, o Templo de Salomão da IURD conta ainda com canais próprios de comunicação como um site (www.otemplodesalomao.com) e perfis nas mídias sociais mais populares (@TemplodeSalomao;facebook.com/templodesalomao; ;instagram.com/TemplodeSalomao), que evidenciam a importância com que este é tratado dentro da dinâmica da IURD e que, logo, os fiéis também devem tratá-lo com a mesma importância. O objetivo deste trabalho é analisar como essas especificidades de tratamento, principalmente no que diz respeito aos canais de interação com os fiéis, contribuem para a criação do imaginário sagrado do Templo. Para tal, faremos uma análise iconográfica de fotografias postadas no perfil mantido na mídia social Instagram combinada com uma interpretação dos comentários postados pelos fiéis. Antes, porém, faremos uma síntese dos significados do Templo para a comunidade judaica dos tempos bíblicos, que nos ajuda a compreender o espaço que o novo Templo construído pela IURD pretende ocupar no imaginário social.

\section{O TEMPLO BÍBLICO}

Conta a narrativa do Antigo Testamento que, após os judeus deixarem a escravidão no Egito, Deus ordenou a Moisés que construísse uma arca de madeira de acácia revestida em ouro. Nessa arca deveriam ser guardadas as tábuas onde ele havia escrito os Dez Mandamentos ditados por Deus, juntamente com um recipiente contendo um pouco do maná que caia do céu e alimentava o povo hebreu em sua peregrinação no deserto, e a vara de Arão, que havia florescido em um sinal divino. Essa arca, contendo todos esses objetos sagrados para o povo de Israel, ficou conhecida como a Arca da Aliança e significava a presença do próprio Deus no meio do povo hebreu.

${ }^{3} \mathrm{O}$ vídeo pode ser acessado em: https://www.youtube.com/watch?v=Xy31ISIJn3U. Acesso em: 29 set. 2015.

Comun. \& Inf., Goiânia, GO, v. 19, n. 2, p. 35-52, jul./dez. 2016 
Inicialmente a Arca da Aliança era colocada numa tenda, conhecida como Tabernáculo, que era transportada por diferentes lugares nas peregrinações do povo hebreu. Quando Davi se tornou rei, instituiu Jerusalém como capital de Israel e mandou trazer a Arca para uma tenda permanente lá construída. Conta a lenda que Davi se incomodava com o fato de morar num castelo enquanto a Arca da Aliança, tão sagrada, ficava numa tenda simples. Então Davi sentiu desejo de construir um templo sagrado onde a Arca pudesse ser colocada, o que só foi concretizado no reinado de seu filho Salomão.

O lugar escolhido para erguer o Templo foi o Monte Moriá, que, também segundo a narrativa bíblica, foi o local em que Abraão, conhecido como o patriarca do povo judeu, iria sacrificar seu filho Isaque a Deus. Construído com madeiras nobres, revestido em ouro e decorado com tecidos finos, o Templo de Salomão, também conhecido como Templo de Jerusalém, passou a ser o centro de toda adoração e de todo o sacrifício feito ao Deus de Israel, a residência do próprio Altíssimo na terra:

E o Senhor apareceu de noite a Salomão e lhe disse: Eu ouvi a tua oração e escolhi para mim este lugar para casa de sacrifício (...) Pois agora escolhi e santifiquei esta casa, para que nela esteja o meu nome perpetuamente; nela estarão fixos os meus olhos e o meu coração todos os dias. (BÍBLIA, 2 Crônicas, 7.12-16)

A citação acima, retirada da Bíblia, demonstra toda sacralidade presente no Templo, imputada pelo próprio Deus ao escolher habitar àquele lugar como Sua moradia terrena e lá ser glorificado.

Quando Israel foi dominada pelos babilônios, por volta de 580 a.C., período que ficou conhecido como Cativeiro na Babilônia, o Templo foi destruído por Nabucodonosor II e a Arca da Aliança foi roubada, não mais sendo possível localizá-la desde então. Décadas depois, com a restauração da nação de Judá, deu-se início à construção de um novo santuário, no mesmo local. Este segundo Templo, na época de Cristo, foi reformado por Herodes, tornando-se muito maior e mais suntuoso do que aquele construído por Salomão. As dimensões do espaço após a reforma é que foram tomadas como parâmetro pela IURD na construção de seu Templo de Salomão em São Paulo. O Templo de Herodes também foi destruído posteriormente, dessa vez pelos romanos, no século I d.C., restando dele apenas uma parte, conhecida como Muro das Lamentações, que ainda hoje é local sagrado e de peregrinação para os judeus do mundo todo.

Além da dimensão divina do Templo, que significava a própria comunicação entre Deus (Javé) e seu povo escolhido (os hebreus), e que regia todas as atividades religiosas em Israel, Martin Volkmann (1990) chama a atenção para os aspectos econômicos e políticos que o Templo também envolvia. Como o Templo era o local onde os sacrifícios feitos a Javé se

Comun. \& Inf., Goiânia, GO, v. 19, n. 2, p. 35-52, jul./dez. 2016. 


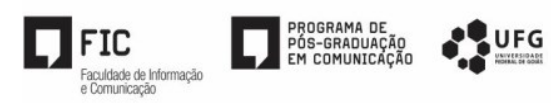

concentravam, no pátio do santuário se proliferou um comércio de animais para sacrifício que fazia com que os preços flutuassem de acordo com a oferta e a procura, chegando a duplicar nos períodos festivos em que o número de rituais desse tipo era maior. Além disso, o Templo, explica o autor, era o local mais seguro para que as pessoas guardassem seus bens valiosos, funcionando como uma espécie de banco controlado pelos sumo-sacerdotes. Estes, por descenderem de famílias da elite, possuíam também importância política.

Vale ressaltar que consideramos aqui um período em que o povo israelita estava dividido quanto à aceitação de uma autoridade monárquica e da escolha de uma cidade onde ele estabeleceria o seu reinado. A elaboração de uma teologia pelo rei com os líderes religiosos, de justificativa da monarquia e da cidade-centro, tornou-se fator harmonizador e introduziu uma nova compreensão de Deus e das práticas religiosas.

Essa tradição nasceu de uma ideologia concebida pelo rei Davi com o apoio de sacerdotes: uma "teologia palaciana" (NOTH, 1985, p. 145-58). Foi a política que se consolidou relacionada à religião que, consequentemente, tomou nova forma. Isso aconteceu quando o rei Davi decidiu levar a Arca da Aliança para Jerusalém e reservar-lhe um local de destaque. A forma de culto que tinha como centro a arca - que era itinerante, não-fixada em local determinado, que acompanhava o povo no seu cotidiano -, foi radicalmente transformada em nome da tradição de países civilizados baseada em santuários locais fixos.

Para a monarquia em Israel se consolidar, centrada em Jerusalém, a Deus foi atribuída a imagem de rei, de governante, que havia escolhido ali como sua cidade e o Templo como local de moradia. Jerusalém tornou-se, portanto, mais do que uma capital, base da monarquia terrena, mas cidade sagrada.

É uma teologia que agregou elementos de outras tradições religiosas, como a da montanha sagrada, divina-uma tradição antiga que interpretava ser a montanha mais alta o local de residência de um Deus. No caso, Jerusalém estava as sentadas sobre o Monte Sião, que nem é dotado de muita altitude, mas ganhou, nessa leitura teológica, o status de montanha sagrada: Jerusalém repousa sobre o monte, é a cidade mais alta e isso a qualificava como cidade real de Deus, moradia terrena dele, de onde exerce o seu governo. Disso deriva a explicação para a arca se fixar naquela localidade e o estabelecimento da necessidade de uma peregrinação até lá para o culto, as festas, as ofertas. Jerusalém passou a ser o único local de culto.

Essa construção teológica reuniu toda a mística, todo o mistério disponível na tradição, para convencer o povo de que era em Jerusalém que a intervenção divina se manifestava. Surgiram as imagens do Santo dos Santos, dos querubins, por exemplo. Além das imagens da 
realeza e do governo (que têm embutidas as de soberania, poder, domínio, trono), este imaginário religioso relaciona as imagens de guerra e exército, também a Deus. Deus está em Jerusalém, portanto, ela não pode ser abalada, ameaçada, porque lá é a cidade dele. Deus faz guerra, protege a cidade santa e exerce vitória sobre os reis estrangeiros por intermédio dos feitos dos reis israelitas terrenos - todos são derrotados.

Daí se verifica como o Templo, na época bíblica, estava na base da organização do povo judeu, alimentando seus mitos fundadores, regendo suas atividades religiosas ao indicar formas de interação com o sagrado, mas também movimentando sua economia e interferindo na vida política dos hebreus. Tudo isso legitimado pelo imaginário do povo de Israel que tomava aquele lugar como sagrado.

A importância do imaginário na construção social será também abordada no decorrer deste artigo. Antes, porém, julgamos necessário traçar uma breve caracterização da Igreja Universal do Reino de Deus para compreender como a construção do Templo de Salomão se insere em suas formulações religiosas.

\section{IURD: UMA IGREJA "RELIGIOFÁGICA}

A Igreja Universal do Reino de Deus foi fundada em 9 de julho de 1977 por Edir Macedo, RR Soares e Roberto Augusto Lopes. No início, RR Soares era o líder máximo da igreja, mas logo foi perdendo espaço para Macedo, que após uma eleição para resolver os impasses internos causados pela concorrência entre os dois, na década de 70 se torna a principal liderança da IURD. Após perder a eleição, RR Soares foi recompensado financeiramente pela Universal e se separou para fundar, em 1980, a Igreja Internacional da Graça de Deus (SOUSA, 2014). Hoje, o número de templos da IURD espalhados pelo Brasil ultrapassa a marca dos seis mil, sendo uma das igrejas que mais cresce no país.

A IURD pertence ao segmento das igrejas neopentecostais. Essas igrejas são caracterizadas por uma exacerbação da guerra espiritual contra o diabo e seu exército de anjos caídos, por enfatizar a Teologia da Prosperidade em suas pregações, por não se prenderem aos estereótipos de usos e costumes de santidade adotados nas demais igrejas pentecostais e por se estruturarem administrativamente como empresas (MARIANO, 2005).

Além dessas características comuns às demais igrejas da vertente neopentecostal, Ari Pedro Oro (2005-2006) caracteriza a Universal como uma igreja "religiofágica" e uma igreja da "exacerbação". Ao propor que a IURD se trata de uma igreja "religiofágica" o autor toma emprestado da biologia o termo "fagocitose", que nomeia o processo pelo qual uma partícula ou um microorganismo é digerido por uma bactéria. O autor explica que a IURD constrói seu Comun. \& Inf., Goiânia, GO, v. 19, n. 2, p. 35-52, jul./dez. 2016. 
universo simbólico a partir de elementos presentes em outras religiões, inclusive naquelas que considera adversárias, como as religiões de matrizes afro, ressignificando-os em seu quadro de sentidos:

Ou, então, segundo a metáfora que venho empregando, ela não somente "engole" as crenças apreendidas de outros segmentos religiosos. Ela também as "digere" e transforma de acordo com o seu próprio "aparelho digestivo". Ou seja, além de "reencontra[r] linhas do universo simbólico brasileiro tradicional [...]" (Sanchis, 1994, p. 53), a IURD vai proceder a sua ressemantização, sobretudo daquelas concernentes às religiões afro-brasileiras (ORO, 20052006, p.323).

Por exemplo, é comum que nos rituais da IURD sejam utilizados elementos típicos das religiões espiritualistas ou do catolicismo popular como sal, arruda, ou que sejam invocadas entidades da umbanda e do candomblé, como pomba-gira, preto-velho, mas, nesse último caso, tomados como espíritos malignos que devem ser combatidos.

Do mesmo modo, a construção do Templo de Salomão com todas as réplicas dos elementos sagrados pode ser vista como mais um exemplo de como acontece essa "religiofagia" praticada pela IURD. Entretanto, diferentemente das religiões afro que são demonizadas no universo simbólico da IURD, os elementos da cultura judaica são tomados como representação máxima do Sagrado na terra, mas completamente diluídos nessa bricolagem de crenças, destituídos de sua função original narrada pelo Antigo Testamento.

A outra característica que Oro aponta, a da IURD como igreja da "exacerbação", indica o modo como ela imprime sua presença no espaço público, principalmente através dos grandes templos e da forte presença midiática para fins proselitistas. De acordo com o autor, a IURD inovou ao realizar estudos para saber o potencial mercadológico do consumo de bens simbólicos antes de instalar suas igrejas em alguma localidade, e também ao ocupar grandes e confortáveis espaços físicos, como cinemas e teatros, para servir de templo religioso, ou ao realizar grandes empreendimentos arquitetônicos para o mesmo fim, como é o caso do Templo de Salomão, o maior e mais importante deles.

Sobre a mídia, o Oro destaca a importância com que esta sempre foi tratada na história da IURD, que hoje é dona de vários veículos de mídia impressa no Brasil e no exterior, da gravadora Line Records e da TV Record, a segunda maior emissora de TV do país. Além disso, a IURD também possui uma forte inserção na internet, com sites próprios e perfis nas principais mídias sociais, nos quais os fiéis podem interagir diretamente com a instituição e também uns com os outros, alimentando o sentimento de pertença destes, como é o caso do perfil que o Templo de Salomão mantém no Instagram, objeto de nossa análise. Para Oro, a IURD se utiliza 
da mídia como um meio de evangelização e, principalmente, como instrumento de marketing e propaganda.

O autor também coloca como características da "exacerbação" praticada pela IURD o superdimensionamento do poder do demônio, a hipertrofia dos rituais de exorcismo e o redimensionamento do significado do dinheiro. No entanto, para os fins da análise em questão, interessa-nos apenas as duas características iniciais que foram detalhadas nos parágrafos anteriores.

Indicados os caminhos que a IURD percorre para compor seu universo de sentidos, faremos uma apresentação do conceito de imaginário que servirá como base teórica para nossa reflexão.

\section{IMAGINÁRIO: UMA CONSTRUÇÃO COLETIVA E TAMBÉM MIDIÁTICA}

Os estudos sobre o imaginário têm início na Antiguidade Clássica. Enquanto para Platão a imaginação era considerada a mais inferior das faculdades, uma fonte de conjecturas que devia ser evitada na busca do conhecimento racional, Aristóteles, pelo contrário, acreditava que esta estava na base do pensamento, pois seria através dela que a alma poderia conhecer e julgar um ser qualquer. O pensamento platônico se sobressaiu ao pensamento aristotélico ao longo dos anos e o papel da imaginação nos processos sociais acabou sendo menosprezado (CUNHA, 2012). Entretanto, nas últimas décadas, autores como Cornelius Castoriadis, Gilbert Durand, Michel Maffesoli, se debruçaram para analisar o lugar que essas construções imaginárias ocupam na organização da sociedade.

Para esses autores, o imaginário é uma construção coletiva que nos possibilita apreender o mundo no qual vivemos. Todas as normas, instituições, valores, formas de expressão, quadros de referência que organizam nossa identidade, que nos permitem ter a consciência do que somos nós e do que é o outro, que nos possibilitam nos situarmos no mudo e falar de alguma coisa, toda sociedade, tudo é resultado dos mitos, das imaginações coletivas produzidas antes de nós. Herdamos esses imaginários das gerações anteriores e o transmitiremos às novas gerações a partir das reapropriações que fizermos no nosso tempo, num movimento perpétuo de produção e reprodução simbólica (CASTORIADIS, 1997).

Assim, contradizendo o que dizia Platão, o imaginário não seria uma fonte de conjecturas, algo oposto ao real, mas algo concreto inserido na realidade e que dá sentido a ela. Como explica Maffesoli:

O imaginário é o estado de espírito de um grupo, de um país, de um Estadonação, de uma comunidade, etc. O imaginário estabelece vínculo. É

Comun. \& Inf., Goiânia, GO, v. 19, n. 2, p. 35-52, jul./dez. 2016. 
cimentosocial. Logo, se o imaginário liga, une numa mesma atmosfera, não pode ser individual (MAFFESOLI, 2001, p. 76).

Para Maffesoli (2001) o imaginário ainda é a aura (no sentido transcendental empregado por Walter Benjamim à obra de arte) de uma ideologia, pois é o que move o desejo de partilha, de estar junto, o sentimento de afeto que explica a adesão para além dos componentes racionais. O imaginário, então, apesar de real, é intangível, pois se constitui de um "momento de vibração comum", de "sensação partilhada" sobre algo (MAFFESOLI, 2001, p. 77).

Como já foi mencionado, somos e herdeiros e transmissores do imaginário coletivo. Essa assimilação e essa propagação se dão por meio das narrativas, transmitidas tanto pela oralidade quanto pelos artefatos técnicos, aqui inclusas as mídias. Maffesoli (2001) chama de "tecnologias do imaginário" esses canais pelos quais o imaginário é produzido e reproduzido, sendo as mídiasparte dessas tecnologias. Para o autor os jornais, a publicidade, a internet, etc., fornecem uma quantidade de material imagético que desperta a sensibilidade de cada um, que faz sonhar, faz vibrar, provoca reações e desperta o sentimento de comunidade:

A técnica é um fator de estimulação imaginal (...) o imaginário, enquanto comunhão, é sempre comunicação. Internet é uma tecnologia da interatividade que alimenta e é alimenta da por imaginários.

Existe um aspecto racional, utilitário, de Internet, mas isso representa apenas uma parte desse fenômeno. O mais importante é a relação, a circulação de signos, as relações estabelecidas. Da mesma forma, a televisão e a publicidade articulam o emocional e a técnica (MAFFESOLI, 2001, p. 80).

Dessa forma, as mídias criam grupos virtuais de afinidades, ou seja, forma, dá liga a comunidades, num constante movimento de alimentar o imaginário coletivo ao mesmo tempo em que é alimentada por ele. $\mathrm{Na}$ internet esse processo de criação de afinidades se torna mais rápido e intenso, pois, como apontado pelo autor, o estar em relação e o compartilhamento de signos estão na constituição do próprio meio. Em nossa análise, buscamos evidenciar esse aspecto pelos vínculos afetivos que os fiéis estabelecem com o Templo de Salomão por meio das imagens divulgadas pelo Instagram.

\section{O TEMPLO DE SALOMÃO NO INSTAGRAM}

O Instagram é uma mídia social que funciona a partir de um aplicativo de celular, cujo principal objetivo é o compartilhamento de imagens. Criada em 2010 pelo norte-americano Kevin Systrome pelo brasileiro Mark Krieger, logo se tornou uma das mais populares do mundo, principalmente entre os mais jovens, que veem nela uma alternativa ao Facebook, mídia social com maior número de usuários. 


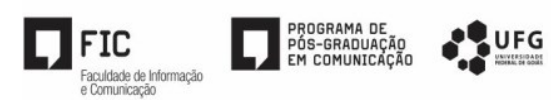

Quem cria um perfil no aplicativo pode postar imagens e pequenos vídeos para uma rede de seguidores, que podem interagir com os conteúdos fazendo comentários ou acionando a opção “curtir" para sinalizar que gostou da publicação. O Templo de Salomão mantém um perfil no Instagram que vem sendo alimentado desde antes de sua inauguração, em julho de 2014 . Na descrição da página, uma inscrição em hebraico que faz referência ao Templo, seguida da frase "Um lugar de paz para a humanidade", que também aparece traduzida para o inglês, saúda quem visita o perfil. A primeira foto foi postada no dia 13 de maio de 2014 e, até a data de produção deste artigo, 03 de julho de 2015, a conta somava 290 publicações e mais de 70mil seguidores.

A grande maioria das imagens divulgadas são fotografias do Templo nos mais variados ângulos e detalhes, acompanhadas por pequenos textos, geralmente versículos extraídos da bíblia, sendo possível encontrar algumas inscrições em hebraico nessas legendas. Em raras ocasiões algumas publicações trouxeram conteúdo diferente, como informações sobre eventos especiais da IURD (cultos, palestras, comemorações, homenagens), ou sobre algum produto midiático ligado à igreja (lançamentos do livro de Edir Macedo, do site oficial do Templo, divulgação do perfil do Templo no Facebook) ou divulgação de algum programa da TV Record cuja temática tivesse alguma relação com o Templo (reportagem do Programa do Gugu sobre o santuário, minissérie Os Dez Mandamentos). O recurso de vídeo também foi pouco utilizado. Desde o lançamento do perfil até o momento de nossa análise, apenas sete foram postados, todos com duração de poucos segundos, exibindo imagens do Templo.

Para nossa análise iconográfica, selecionamos a imagem mais curtida de cada mês, nos três meses posteriores à inauguração do Templo (agosto, setembro e outubro de 2014), pois essas marcas indicam que os conteúdos despertaram algum sentimento afetivo nos usuários da rede que serviu para alimentar sua relação com o Templo.

A primeira foto selecionada foi postada no dia 03 de agosto de 2014 e contava, até o dia 03 de julho de 2015, com 2.187curtidas e 79 comentários. Como é possível ver abaixo, a imagem mostra a entrada do Templo e, diferentemente das outras igrejas da IURD, na fachada não existe nenhuma identificação que revele que o edifício se trata de uma igreja evangélica, muito menos da Universal. Isso reforça a ideia de que aquele se trata de um lugar realmente sagrado, acima de qualquer religião, que assim como nos tempos bíblicos, é a verdadeira morada de Deus na Terra.

Toda essa aura de sacralidade é intensificada pelo ângulo explorado pelo enquadramento da fotografia, que permite que quem olhe tenha dimensão da grandiosidade da obra. A iluminação também contribui para essa sensação ao permitir que os vários detalhes, o

Comun. \& Inf., Goiânia, GO, v. 19, n. 2, p. 35-52, jul./dez. 2016. 
dourado no corrimão e na porta, se sobressaiam e assegurem toda a imponência do Templo. $\mathrm{O}$ enquadramento e a iluminação produzem uma sensação de que o Templo e o céu, de uma coloração tão intensa na foto, estão se tocando, como se a construção fizesse mesmo essa ligação entre a Terra e o mundo sagrado. Essa conexão ainda é reforçada pela legenda que acompanha a foto, onde se lê um versículo bíblico seguido da frase "O Templo é o lugar de encontro com Deus, para que Ele possa HABITAR EM VOCÊ!"

Figura 1 - Foto da fachada do Templo de Salomão postada no dia 03/08/2014

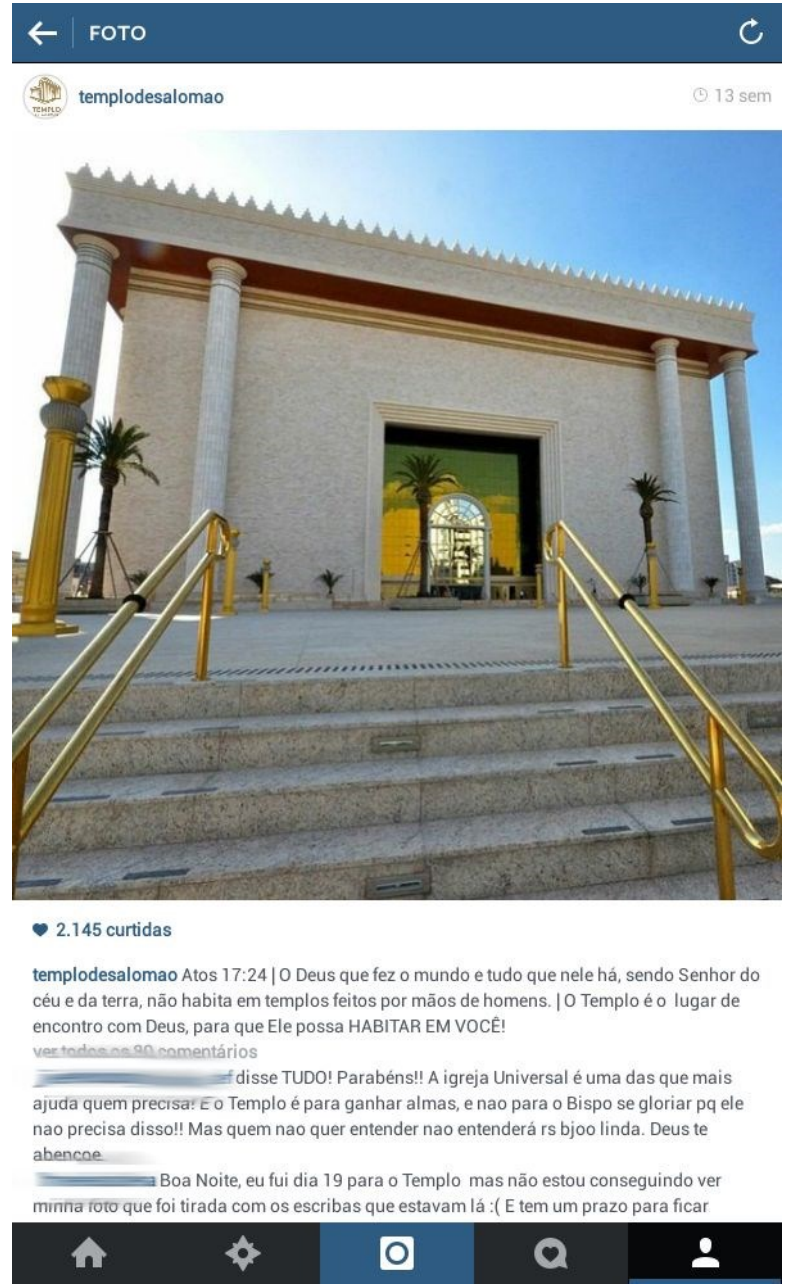

Fonte: instagram.com/templodesalomao/

A segunda foto selecionada foi postada no dia 06 de setembro de 2014 e contava, até o dia de nossa análise, com 1.976 curtidas e 29 comentários. A imagem mostra, em detalhe, um dos dez candelabros existentes nas paredes laterais internas do Templo. Nos tempos bíblicos esses candelabros, menorahs, eram usados para a iluminação interna do santuário. Em toda a narrativa bíblica é comum encontrar menções a esse objeto, relacionando-o a algum contexto 
de comunicação com o mundo sagrado, como quando Deus fala a Moisés que construa um candelabro de ouro para o Tabernáculo que guardava a Arca da Aliança.

Candelabros também aparecem na narrativa bíblica em contextos de visões proféticas, de adoração profunda, de representação da verdadeira e divina luz que provém dos céus. No Templo da IURD, a iluminação fica a cargo das 10 mil lâmpadas de LED instaladas, mas réplicas dos candelabros dourados que existiam no primeiro Templo também foram colocadas, resgatando o significado do candelabro como elemento que atesta a presença do divino.

Figura 2 - Foto da fachada do Templo de Salomão postada no dia 06/09/2014

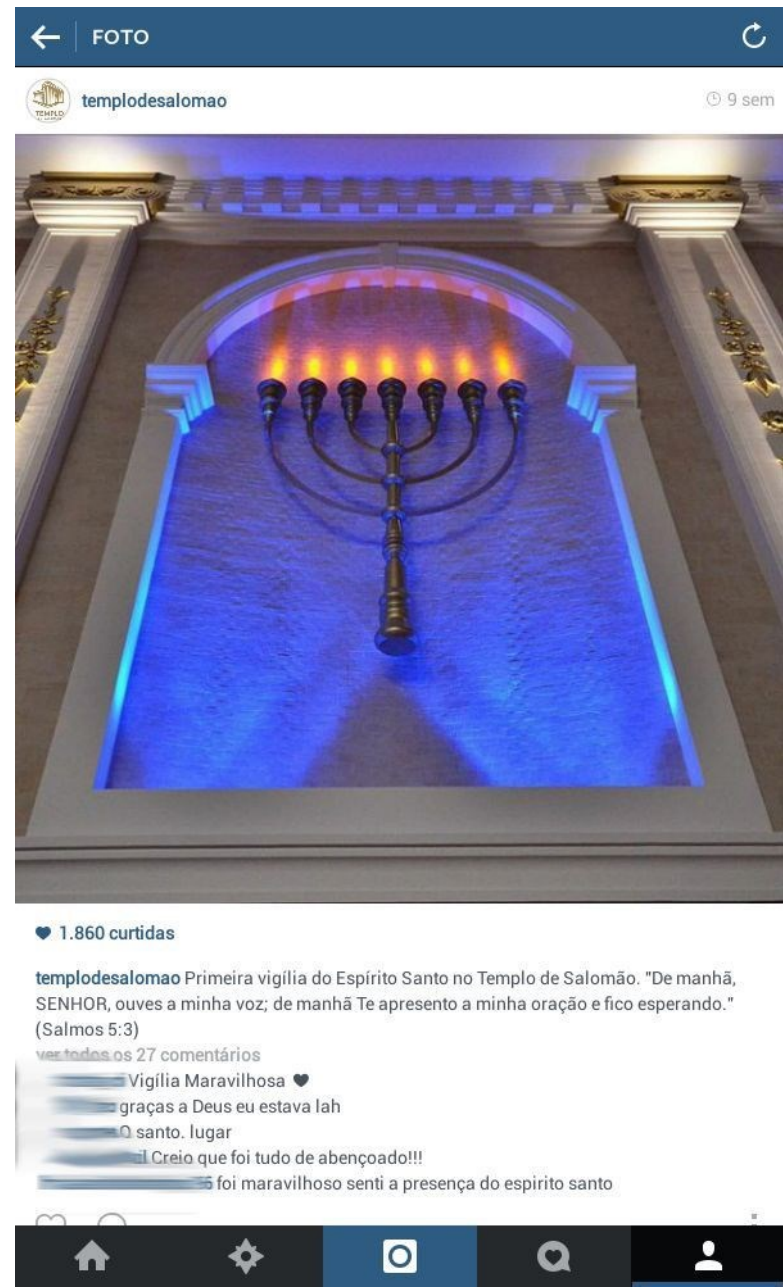

Fonte: instagram.com/templodesalomao/

$\mathrm{Na}$ foto, o jogo de luzes valoriza as chamas, que simbolizam a presença de Deus. A legenda é uma chamada para a primeira vigília do Espírito Santo (que na narrativa bíblica também se apresenta ao mundo terreno como fogo), seguida por um versículo. Percebe-se que a postagem combina vários elementos imagéticos e textuais (o candelabro sagrado, o fogo, a menção ao Espírito Santo) para reafirmar que o espaço é uma continuação do Templo bíblico, morada do verdadeiro Deus e por isso, também deve ser venerado.

Comun. \& Inf., Goiânia, GO, v. 19, n. 2, p. 35-52, jul./dez. 2016. 


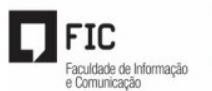

A terceira foto aqui selecionada, postada no dia 25 de outubro de 2014, apresentava 1.447 curtidas e 29 comentários até o dia da análise. Nela se vê uma das laterais do templo, com as colunas externas que o sustentam, e um grande candelabro.

Figura 3 - Foto da lateral do Templo de Salomão postada no dia 25/10/2014

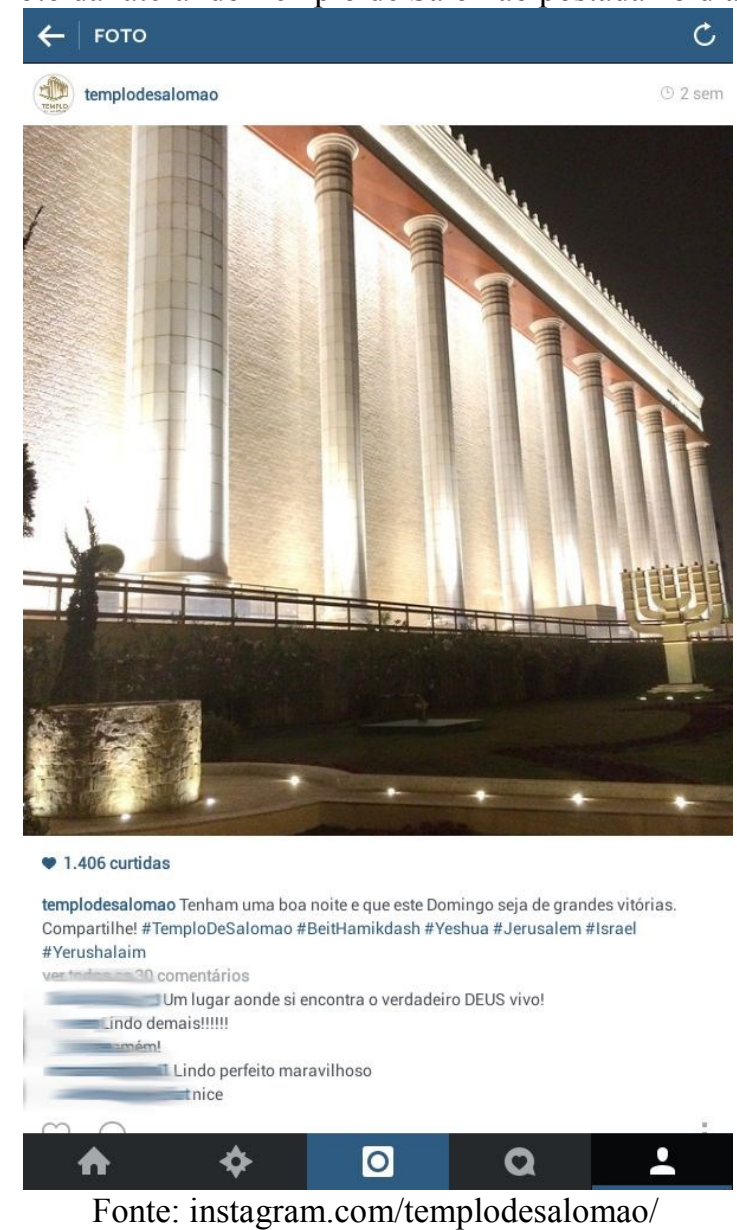

O candelabro, como explicamos, na narrativa bíblica está relacionado à presença de Deus e a momentos de interação com o sagrado, então aqui, novamente, se faz uso dele para acionar esse imaginário de "lugar santo" e transmiti-lo para o Templo da IURD. Embora seja noite, o Templo aparece muito bem iluminado na foto compartilhada, podendo quem olha ter dimensão de todo o detalhamento da edificação e de toda sua beleza. Novamente o ângulo do enquadramento privilegia a imponência do prédio. Diferente das demais fotos, esta não traz nenhuma referência da Bíblia na legenda que a acompanha. $\mathrm{O}$ texto apenas deseja boa noite aos fiéis.

\subsection{A INTERAÇÃO DOS FIÉIS}

Na primeira imagem, como mencionamos, existiam 80 comentários até o momento de nossa análise, a maior parte deles positivos. Poucos comentários, alguns escritos pela mesma

Comun. \& Inf., Goiânia, GO, v. 19, n. 2, p. 35-52, jul./dez. 2016. 
pessoa, apresentavam alguma crítica negativa. Os demais são de pessoas respondendo "amém!" ao versículo que acompanha a foto, ou de pessoas reafirmando a sacralidade do lugar e manifestando desejo de estarem presentes no Templo. Algumas delas, inclusive, rebateram aos comentários negativos afirmando que aquele é sim um local onde Deus habita, como habitou o Templo em Israel nos tempos bíblicos.

Figura 4 -comentários retirados da primeira imagem analisada, que mostra como os seguidores apreendem e reproduzem o discurso de sacralidade proposto para o Templo.

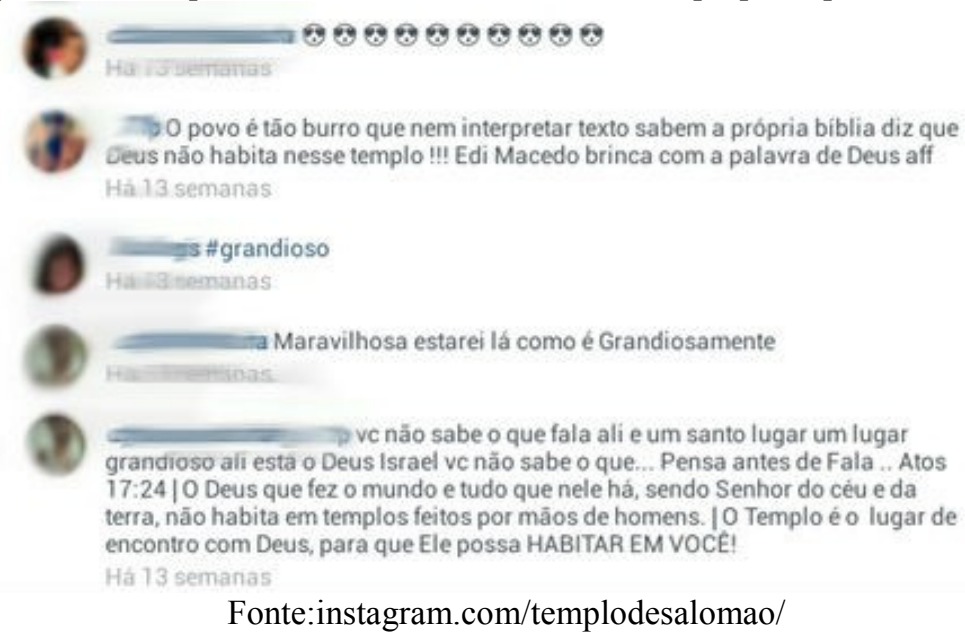

Na segunda imagem, dos 26 comentários recebidos, nenhum apresentava conteúdo negativo. A maioria deles era de pessoas que visitaram o Templo e estavam expressando sua emoção em terem estado lá, afirmando vivenciar experiências com o Sagrado ao frequentar o santuário. Nessa imagem, chama a atenção um comentário feito em hebraico, que faz referência à presença de Jesus. O comentário evidencia que assim como a IURD resgata os elementos do Antigo Testamento para compor a aura de sacralidade de seu Templo, também seus seguidores fazem o mesmo movimento e se utilizam da língua da época, a mesma falada pelos sacerdotes do Templo de Jerusalém ao entoar suas orações, para interagir com santuário da IURD. Assim, por meio dessas ressignificações simbólicas, a IURD e seus fiéis constroem coletivamente o imaginário de sagrado do Templo ao recuperar esses símbolos e transferi-los para o momento presente, numa tentativa de trazer toda a mística que existia no Templo de Jerusalém para o Templo de Salomão da IURD.

Comun. \& Inf., Goiânia, GO, v. 19, n. 2, p. 35-52, jul./dez. 2016. 
Figura 5 - Comentários retirados da segunda imagem analisada; o do meio, feito em hebraico.

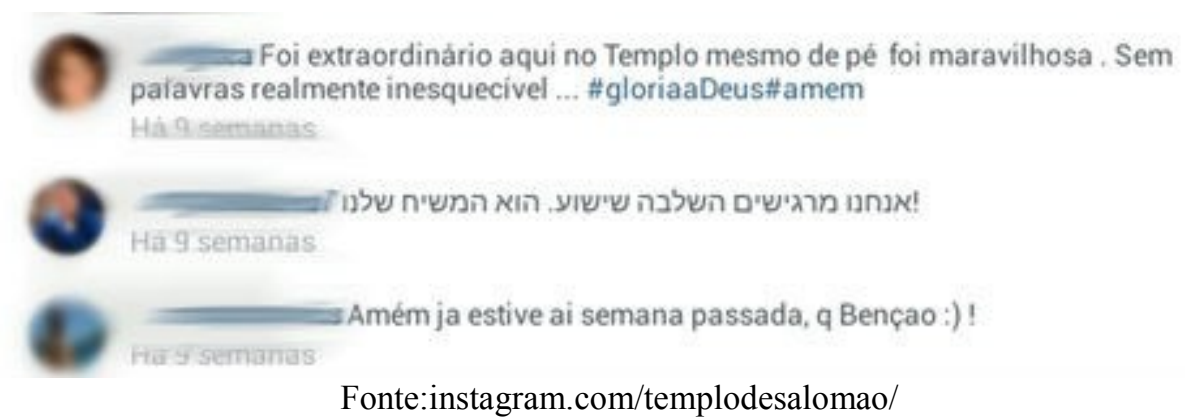

Os 29 comentários recebidos na terceira imagem analisada também não apresentavam nenhuma referência negativa ao Templo. Todos eles se assemelhavam aos comentários das postagens anteriores, ora demonstrando adesão ao texto da legenda, ora afirmando que o Templo é um local divino. O diferencial ficou por conta dos comentários feitos por uma mesma pessoa que se pedia aos demais que orassem pelas igrejas do Rio de Janeiro que, segundo ela, estavam sendo ameaçadas e fechando as portas. Alguns comentários também faziam menção de apoio à candidatura do Bispo Marcelo Crivella, um dos principais líderes da IURD, para o governo do Rio de Janeiro. Nota-se com isso que os seguidores interagem com o conteúdo e também entre si, pois reconhecem aquele ambiente como familiar e como um espaço onde podem partilhar seus sentimentos com outros pares. Assim, percebemos o potencial que a mídia tem, conforme apontado por Maffesoli (2001), de criar comunidades virtuais afetivas e alimentar seus imaginários.

\section{A TÍTULO DE CONCLUSÃO}

Como se pode perceber, a IURD se utilizou de um imaginário de sagrado que já estava presente em nossa cultura por meio da narrativa bíblica e o ressignificou em sua configuração religiosa. Por esse imaginário, tudo o que se liga à história do antigo povo hebreu, como seus objetos de culto, seu santuário e sua língua, representa a verdadeira forma de interação com o mundo divino, pois é aquela que Deus, ao aparecer para seus profetas no Antigo Testamento, ordenou que fizesse. A IURD, ao construir réplicas fiéis desses elementos, mas dissociadas de seu contexto histórico, resgata esse imaginário e se engaja numa tentativa de reinseri-lo em nosso tempo presente ao propor que toda a aura de sacralidade que envolvia esses objetos no passado seja transferida para suas réplicas.

Outro elemento a ser observado é que a simbologia em torno do Templo de Salomão busca relação com o passado de glória e riqueza de Israel relacionado à monarquia e à construção do templo de Jerusalém. Segundo os estudiosos do AT, o ouro e a ostentação

Comun. \& Inf., Goiânia, GO, v. 19, n. 2, p. 35-52, jul./dez. 2016. 


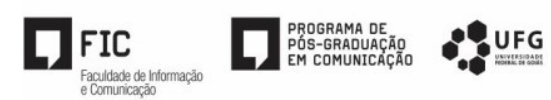

relacionados a estes elementos fazem parte do imaginário das tradições pós-exílicas dos sacerdotes do antigo Israel e pouco tem de relação com a história do surgimento destes objetos no deserto (mais simplicidade, própria do contexto).A imagem da arca mesmo teria desaparecido já no período da divisão dos dois reinos, mas no século XXI ressurge não só no Templo da IURD, mas também em nomes de grupos musicais, de igrejas do universo pentecostal e nos altares com todo o brilho do imaginário pós-exílico. Nesse sentido, a mensagem de prosperidade, glória e vitória, tão caras à teologia da IURD, passam a ter estreita relação com estes símbolos visuais.

Nesse processo, a mídia adquire um papel fundamental, pois conforme apontado por Maffesoli (2001) esta, assim como a oralidade, atua nos movimentos de apropriação e transmissão dos imaginários, pois se alimenta dessas construções coletivas ao mesmo tempo em que é alimentada por elas. Esse movimento de retroalimentação ficou evidente em nossa análise, pois como se viu, todos os conteúdos produzidos para serem compartilhados pelo perfil do Templo de Salomão no Instagram (imagens e textos das legendas) trabalham no sentido de explicitar a grandiosidade do santuário, privilegiando seus detalhes, explorando formas de enquadramento e iluminação que ressaltem sua beleza e relacionando-as com textos, inclusive retirados da própria Bíblia Sagrada, que legitimam a sua existência enquanto morada oficial de Deus na terra.

A divulgação desses conteúdos envoltos por esse discurso de sacralidade desperta sensações afetivas nos seguidores do perfil, que em suas interações demonstram adesão ao universo simbólico que este propõe. Nos comentários, o sentimento de partilha e de pertencimento fica evidente por meio dos vários relatos de agraciamento daqueles que estiveram presentes no santuário e que atestam a veracidade da presença do sobrenatural, e também nas falas daqueles que expressam o seu desejo de visitar o espaço, que é realmente visto como um lugar sagrado. A existência de comentários negativos que são prontamente rebatidos pelos seguidores indica como essa aura de sacralidade que as imagens tentam transmitir é legitimada por aqueles que partilham do mesmo discurso, que o defendem com suas paixões.

O perfil do Templo de Salomão no Instagram se apresenta para aqueles que partilham desse imaginário de sagrado como uma extensão virtual do próprio Templo, como um espaço onde podem demonstrar sua adesão a esse universo simbólico e dividir suas sensações com outros pares, reforçando assim seus laços afetivos de pertencimento. O perfil analisado é um indicativo do potencial que a mídia, enquanto tecnologia do imaginário possui, de alimentar 
imaginários e se alimentar deles, e de contribuir para a criação de comunidades afetivas, como pudemos atestar em nosso estudo.

\section{REFERÊNCIAS}

BATISTA JR. J. Detalhes exclusivos do Templo de Salomão, nova sede da Igreja Universal. Veja, São Paulo. 30 maio 2014. Disponível em: <http://vejasp.abril.com.br/materia/templo-de-salomaoigreja-universal>. Acesso em: 03 nov. 2014.

BÍBLIA. A.T. 2 Crônicas. Português. A Bíblia. Tradução de João Ferreira de Almeida revista e atualizada no Brasil. 2. ed. São Paulo: Sociedade Bíblica do Brasil, 1993, cap. 7, vers. 12-16.

CASTORIADIS, C. As encruzilhadas do labirinto. II. Domínios do Homem. Rio de Janeiro, 1987. p. $225-243$

CUNHA, M. N. Da imagem, à imaginação e ao imaginário: elementos-chave para os estudos de comunicação e cultura". In: BARROS, L. M. de. Discursos midiáticos: representações e apropriações culturais. São Bernardo do Campo: Editora Metodista, 2012, p. 33-48.

CUNHA, M. N. A interseção mídia religiosa e mercado e a ressignificação de signos bíblicos pelos evangélicos. Relegens Thréskeia, v. 03, n. 01, jan./jun., 2014. Disponível em: $<$ http://ojs.c3sl.ufpr.br/ojs2/index.php/relegens/article/view/37688>. Acesso em: nov. 2014.

GOMES, H. S. Jovens brasileiros trocam Facebook por aplicativos de mensagens. G1, 25 nov 2013. Disponível em: <http://g1.globo.com/tecnologia/noticia/2013/11/jovens-brasileiros-trocam-facebookpor-aplicativos-de-mensagens.html>. Acesso em 03 nov. 2014.

INSTAGRAM atinge marca de 200 milhões de usuários ativos por mês. G1, 26 mar. 2014. Disponível em: $<$ http://g1.globo.com/tecnologia/tem-um-aplicativo/noticia/2014/03/instagram-atinge-marca-de200-milhoes-de-usuarios-ativos-por-mes.html>. Acesso em: 03 nov. 2014.

MAFFESOLI, M. O imaginário é uma realidade. FAMECOS, Porto Alegre, 15, ago 2001. Entrevista concedida a Juremir Machado da Silva. Disponível em:<

http://www.revistas.univerciencia.org/index.php/famecos/article/view/285/217>. Acesso em: nov. 2014.

MAFFESOLI, M. A comunicação sem fim (teoria pós-moderna da comunicação). FAMECOS, Porto Alegre, 20, abr 2003, p. 13-20. Disponível

em:<http://revistaseletronicas.pucrs.br/ojs/index.php/revistafamecos/article/viewFile/3198/2463>. Acesso em: nov. 2014.

MARIANO, R. Neopentecostais: sociologia do novo pentecostalismo no Brasil. 2 ed. São Paulo: Loyola, 2005.

NOTH, M. Estudios sobre el Antiguo testamento. Madri: Ediciones Sigueme, 1985. (Biblioteca de estudios biblicos, 44).

ORO, A. P. O neopentecostalismo macumbeiro. Revista USP, São Paulo, n.68 dezembro/fevereiro 2005-2006, p. 319-332. Disponível em: <http://www.usp.br/revistausp/68/27-ari-oro.pdf $>$. Acesso em: 03 nov. 2014.

SOUSA, M. T. As narrativas do reino: análise narrativa de programas televisivos da igreja universal nas madrugadas mineiras. Dissertação de Mestrado em Comunicação Social. Programa de Pósgraduação em Comunicação Social da Universidade Federal de Minas Gerais (UFMG), Belo Horizonte, Brasil, 2014.

Comun. \& Inf., Goiânia, GO, v. 19, n. 2, p. 35-52, jul./dez. 2016. 
SOUZA, B. 20 coisas surpreendentes sobre o templo da Igreja Universal. Exame, 25 jul 2014.

Disponível em: <http://exame.abril.com.br/brasil/noticias/20-coisas-sobre-o-enorme-novo-templo-daigreja-universal>. Acesso em: 03 nov. 2014.

TEMPLO de Salomão. Disponível em: $<$ http://www.otemplodesalomao.com>. Acesso em: 03 nov 2014.

VOLKMANN, M. Jesus "destruiu" o templo: a igreja o reconstruiu? Estudos Teológicos, v. 3, n. 30, p. 244-255, 1990. Disponível em:

$<$ http://periodicos.est.edu.br/index.php/estudos_teologicos/article/viewFile/1043/1003>. Acesso em: 03 nov. 2014.

Recebido em: 21/07/2015

Aceito em: 16/11/2015

Publicado em: 31/12/2016

Comun. \& Inf., Goiânia, GO, v. 19, n. 2, p. 35-52, jul./dez. 2016. 